\title{
Integration of Ignatian values in the development of algebraic thinking via utilization of quasi-variables: A lesson study
}

\author{
Marian Grace Veloso ${ }^{1}$, Lucio Landanganon ${ }^{2}$, Raquel Lamanilao ${ }^{3}$, Levi Elipane ${ }^{4}$ \\ ${ }^{1,2,3}$ Grade School Faculty, Ateneo de Davao University, Davao City, Philippines \\ ${ }^{4}$ Philippine Normal University, Metro Manila, Philippines
}

\section{Article Info \\ Article history: \\ Received Jan 17, 2021 \\ Revised Aug 22, 2021 \\ Accepted Sep 8, 2021}

\section{Keywords:}

Algebra

Arithmetic

Balancing method

Ignatian value

Lesson study

\begin{abstract}
This paper reflects on the outcome of lesson study in teaching the concept of algebraic equations utilizing quasi-variables. It also concurrently examines the integration of Ignatian values and social issues in learning the said concept. This study aimed to establish a culture of planning, collaboration, and reflection in developing the understanding and relevance of mathematical concepts in grade school through lesson study. The study showed how the process of lesson study was done given the following phases: planning phase, implementation phase, and post-lesson reflection and discussion phase. Emphasis on the planning phase was given on the details of the lesson design which aimed to integrate Ignatian values in the discussion while developing algebraic thinking from quasi-variable thinking delivered in the implementation phase. Findings highlighted on three statements: i) Collaborative lesson planning nurtures a deeper sense of scholarship and collegiality; ii) Building algebraic thinking from quasi-variable (arithmetic) thinking is a viable strategy for understanding the concept of algebraic equation; and iii) Looking into the "big picture" and responding to relevant social issues could strengthen meaning - integration of Ignatian values. Strong collaboration and communication among teachers in creating detailed lesson design enabled more meaningful learning among pupils. Research revealed the significant role of lesson study in creating meaningful strategies and activities which provided efficient structure in developing a chosen lesson topic. It does not only focus on the nature of the topic but also include making meaningful connections to the real world and integrate values.
\end{abstract}

This is an open access article under the CC BY-SA license.

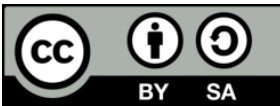

\section{Corresponding Author:}

Marian Grace Veloso

Mathematics Department

Ateneo de Davao Grade School

McArthur Highway Matina, Davao City, 8000, Philippines

Email: mgtveloso@addu.edu.ph

\section{INTRODUCTION}

Formation in faith and values is an integral dimension of learning in a Jesuit institution aside from the transmission of knowledge and skill [1]. Reflection becomes a pivotal point for Jesuit educators to nurture the holistic growth of the students. The values that Jesuit schools aim to instill among its students are described as the Ignatian values which are rooted in the experiences of St. Ignatius of Loyola, the founder of the Jesuit schools. It is a must for teachers to integrate Ignatian values in creating and developing lessons. These values are embedded in classroom interactions, especially in providing relevant experiences to the students which lead students to delve deeper into the subject into the subject itself and make more meaning. These are important stages of the Jesuit schools' pedagogy called the Ignatian pedagogical paradigm (IPP) 
[2]. Based on this paradigm, learning is situated in a specific context, rooted in previous experience and new experiences deepened by reflection. This knowledge is made meaningful by putting it into action and making an explicit evaluation of those actions and the degree to which learning has occurred [3].

In the many years of experiencing integration of Ignatian values in each lesson, the struggle of most teachers is integrating it spontaneously in the discussion [4]. Often, math teachers present situations and ask students to specify the value and Ignatian value being portrayed in the situation. This strategy has been observed to be ineffective since the pupils just tend to guess and state generic explanations to justify the choice. Hence, the integration has been shallow enough to not push students to take action based on the mathematical algorithm learned, which is the goal of the IPP. This struggle is evident in the study on the influence of Ignatian values on faculty roles, which showed that the teachers' difficulty lies in integrating the values in the lesson in a way that it is not forced [5]. This makes teaching in the mathematics department a real challenge aside from the subject's nature. For teachers not to use this strategy, it was suggested that a problem-solving strategy would be used in integrating values in the math classroom [6], [7]. The concept must be embedded in real-life situations, so that the students can apply a mathematical algorithm in making decisions. One goal of this study is to be able to figure out ways to find effective ways to integrate Ignatian values smoothly in the math classroom.

Mathematics starts with the basic knowledge of arithmetic and utilizes this as a foundation for introducing and teaching algebra. The shift from arithmetic to algebra is difficult, but it is an essential step for mathematical progress [8]. By the time pupils start learning algebra, they are expected to have reached proficiency in arithmetic concepts. A study has shown that students' errors in algebra can be attributed to the fundamental differences between arithmetic and algebra [9]. For example, if pupils think algebraically, they should scrutinize some concepts taught in early-grade mathematics (arithmetic) to manage algebraic symbolism [10].

Pupils cannot understand the relationship between two quantities (arithmetic and algebra) because of the flawed foundation of the arithmetic-algebraic connection in situations [11]. It was argued in a study that students have difficulty in moving forward to learning algebra because of their poor foundation of prealgebra concepts like operations on whole numbers and fractions and operations on integers [12]. The generalizing relationship of numbers is necessary for the development of algebraic thinking among pupils [13]. Algebraic thinking is the identifying, classifying, and labeling of sameness and difference while making distinctions in the student's mind [14]. The focus on arithmetic thinking is merely calculating a numerical answer to solve a problem. On the other hand, algebraic thinking focuses on relations and operations [15].

This article reports a lesson study (LS) that aimed to utilize quasi-variables and the balancing method in establishing a relationship between variables. Lesson study is one practice where teachers can grow by learning from each other, given the right opportunity and context. It is a Japanese form of professional development that focuses on the collaborative study of live classroom lessons and has spread quickly worldwide [16]. It is now being introduced [17], [18] and institutionalized in the Philippines [19]. It is deemed that engaging in lesson study provides opportunities for teachers to develop deep discourse on the teaching of mathematics [20]. Lesson study was used in this study to support a smooth transition from arithmetic thinking to algebraic thinking and to make meaningful connections between previous knowledge and new knowledge while integrating Ignatian values and social issues in the discussion. Finally, this study provided evidence on how lesson study practice affects instruction and pupils' way of thinking.

\section{RESEARCH METHOD}

Lesson study falls under the category of classroom-based research. In this light, this study follows a qualitative approach to render in-depth and focused analysis of data coming from a specific research lesson for the whole process of lesson study [21]. Transcripts and video recordings of teachers' collaborative planning, classroom observations, and post-lesson discussions were analyzed, together with artifacts from the students' works during the research lesson. Thematic analysis was generally done to generate the findings for the study. This method identifies and analyzes patterns of meanings in qualitative data [22]. The themes that emerge after analyzing the reflections and comments during the post-conference are: how the practice of lesson study helped the teachers in developing the lesson; how algebraic thinking was built from quasivariable thinking; how the concept of algebra was strengthened with the integration of Ignatian values through discussion of relevant social issue; and the teachers' role in developing critical thinking of the pupils.

\subsection{Planning phase}

Three out of four members of the research team (the authors of this paper), are grade six math teachers of Ateneo de Davao University - Grade School Unit, Matina, Davao City, Philippines. The plan to conduct this research started when the authors attended a seminar-workshop on lesson study held on January 
3-5, 2018 at the Ateneo de Davao University, Philippines. The workshop emphasized the importance of lesson study, its advantages, and challenges. As an output, participants identified learning content that would be used in the research lesson. The lesson study was materialized with the full support of the headmaster and the subject area head for mathematics. The research followed the essential process in doing lesson study, namely: i) planning phase, ii) implementation of research lesson phase and, iii) post-lesson reflection and discussion phase [23]. The documentation of this lesson study was facilitated by the fourth author of this article, who served as the resource person during the 3-day seminar workshop on lesson study.

This lesson study was designed to help pupils develop algebraic thinking, specifically recognizing relationships, generalizing, and analyzing how values change when exploring algebraic equations with two unknown variables. The researchers collaboratively planned for two weeks, at least twice a week to develop an effective lesson plan intended for grade six pupils. Part of the planning required the research group to comment and give suggestions about the lesson prepared by a group member and discuss thoroughly how the group could implement the lesson logically and effectively within a 50-minutes period. Moreover, the assigned teacher for the research lesson performed an initial dry run with the presence of the team and subject area head for math to anticipate and unlock some difficulties that the teacher may encounter.

\subsection{Implementation of research phase}

The research lesson was implemented on February 12, 2018, with the participation of 40 grade six pupils from Class St. Francis Xavier of the Ateneo de Davao Grade School. Fourteen teachers observed the lesson's implementation, five administrators all from Ateneo de Davao University-Grade School Unit (AdDU-GS), and a professor from the University of the Philippines (UP). Each observer was provided with a copy of the lesson plan as his/her guide for their observation. The video camera was used to record the actual implementation of the lesson.

Prior to the actual observation, the observers were oriented on what to do during observation. Focus on pupils' responses, engagement, and interactions were given emphasis. Observers were also informed to refrain from helping pupils who may ask for help in answering the task given to them. The observers were encouraged to take notes of their insights and suggestions.

The teacher implemented the research lesson within a 50-minutes period. The lesson started with activating pupils' prior knowledge, which helped the pupils connect to the proper lesson - the algebraic equations with two unknown variables. A problem situation relevant to a social issue was presented as a vital part of the lesson to connect the learning experience to broader aspects and infuse Ignatian values. In the lesson proper, the teacher provided the pupils with activities that would be done by pair. Thought-provoking questions relevant to the given activities were given which led the pupils to make statements about relationships of two different variables in the algebraic equation and hypothesize whether the relationship of two variables in the equation will always hold true at all times. The lesson was formally closed using the Exit Card in which pupils were given the opportunity to answer the questions written on a strip of paper.

\subsection{Post-lesson reflection and discussion phase}

After the implementation of the lesson, the researchers and the observers convened for the postlesson discussion, insights, and reflection. This part is vital in a lesson study because this is a venue where the implementers and observers will investigate the executed lesson and focus on how it can be improved [24], [25]. The research lesson implementer shared the experiences, insights, and reflections gathered from the research lesson which started from the planning phase to the implementation of the lesson. Afterward, the observers shared their insights, reflections, observations, impressions, and recommendations on the implementation of the research lesson.

\section{RESULTS AND DISCUSSION}

Three emergent perspectives were evident in the conduct of the lesson study: i) Collaborative lesson planning and development nurtures a deeper sense of scholarship and collegiality; ii) Building algebraic thinking from quasi-variable (arithmetic) thinking is a viable strategy for students to make sense of algebraic equations; and iii) Looking into "bigger picture" and responding to relevant social issues could strengthen meaning-integration of Ignatian values.

\subsection{Collaborative lesson planning nurtures a deeper sense of scholarship and collegiality}

Most of the positive feedbacks were about how the lesson plan used in the research lesson was carefully and collaboratively done. The observers noticed that the lesson plan was developed through research and collaboration and not just the typical textbook-based plan. The lesson study team generally found the exercise of collaboration enriching. Although challenges arose along the way, the process of 
thinking, re-thinking and revising the research lesson plan as a group resulted in a lesson plan that is a product of the expertise of several minds. According to one of the lesson study participants:

"There was 'no monopoly of knowledge' among the team members. Every member of the LS team felt competent and confident to give his/her bright ideas anytime along the way."

This supported the claim that lesson study develops collaboration among teachers in planning, implementing and evaluating a lesson [26], [27]. A deeper sense of collegiality was nurtured in the process, and at the same time, the level of knowledge of the teacher participants were enhanced due to deepening of the content to teach through lesson study.

In the implementation of the research lesson, observers' comments and feedback focused on the following: i) content that is focused on developing algebraic thinking from quasi-variable thinking; ii) meaning that is focused on connectedness of algebra to broader aspects (social issues), and infusion of Ignatian values, also teacher role in developing pupils' critical thinking. It was observed that the day's lesson objectives were not explicitly mentioned in the beginning thus posting some thoughts among the observers as to which would be more effective, saying the objectives at the beginning or allowing the pupils to discover it along the way.

It was also emphasized that the teacher's chosen activity to use in presenting the concept of "balancing" was somewhat explicit. According to two of the observers, who were also science teachers, though the concept was not freely given, it might have been better if the pupils discovered the "balancing" in mathematics themselves. The choice of activity is very important.

On several occasions, pupils were not given enough opportunity to strategize in solving the problems presented. According to one of the observers, pupils should be given ample time and chance to think critically themselves. Developing critical thinking entails time and effective art of questioning [28]. It was even an opportune time for pupils to make connections with other disciplines like science given enough time to explore and remember.

Observing how pupil engagement transpired along the process of doing the prepared tasks, it was apparent that pupil engagement increased from Task 1 where the situation presented limited the pupils to giving only one exact answer to Task 2 where pupils were allowed to explore and elicit several possible answers. Confidence among pupils also increased as they were given opportunities to list down several possible answers and when they were already able to see the pattern and relationship of the variables and constants involved.

\subsection{Building algebraic thinking from quasi-variable thinking is a viable strategy for students to make sense of algebraic equations}

The pupils were able to differentiate algebraic expressions from algebraic equations easily given the activity of categorizing examples. The teacher asking for the difference between the two did follow up questions. Specifically, to emphasize on visual difference, the teacher asked, "What do you see in algebraic equations that cannot be found in algebraic expressions?" According to the observers, this process was done "too explicitly". Somehow, it was too leading. Recommendations were to allow the pupils to categorize and differentiate algebraic expressions from algebraic equations themselves through a rumble of such examples.

Understanding the relationship between constants, variables, and building the concept of equalities through the balancing method started with an activity involving an actual balance weighing scale. The pupils found ease in giving combinations of numbers that will make the scale balanced. Sample outputs were the following:

$$
\begin{aligned}
& 50=20+20+10 \\
& 50=20+20+5+5 \\
& 20=10+10 \\
& 20=5+5+5+5
\end{aligned}
$$

Pupils were able to identify that the fulcrum in the balance scale is the same as the equal sign "=" written in an equation. It is the symbol that tells that the equation's left side's value is the same as the value on its right side. Progressing to working with algebraic equations, pupils were able to identify different values of the variables that will make the equation "balanced". When they were asked to give the relationship of the pairs of variables they mentioned, pupils were able to identify them with ease. Although task 1 was limiting, similar task 2 gave the pupils more liberty to think and give endless possible pairs of variables or combinations yet come up with the same relationship between the variables. In the end, when asked the 
question, "So, when does the relationship change?" pupils were able to draw the statement that, "The relationship of the variable changes when the value of the constants is changed or altered." This is consistent with the result where a child drew a picture of a balance scale to show how it affects the balance if she alters the expressions on each side [29].

\subsubsection{Generalizing numerical relationships: Building algebraic thinking}

Table 1 shows the response of one pupil in one of the given tasks. The pupil understands that if there are 160 wafers to be given to 20 children, each child will receive an " $x$ " number of wafers. However, when the number of children becomes 40 each child will receive a " $y$ " number of wafers. The pupil was able to identify that the value of $\mathrm{x}$ is twice $\mathrm{y}$.

Table 1. Pupil's response

\begin{tabular}{lll}
\hline \multicolumn{3}{c}{ Mathematical sentence: $20 \times \mathrm{A}=40 \times \mathrm{B}$} \\
Total number of wafers & 20 children & 40 children \\
\hline 160 & $20(\mathrm{X})=160$ & $40(\mathrm{Y})=160$ \\
\hline Relationship between A and B: X is twice Y's value
\end{tabular}

Table 2 shows the response of another pupil. If there are 160 wafers to be given to 20 children, each child will receive eight wafers. However, if there are 40 children, each child will receive only four wafers. The pupil made the total number of wafers 80 . If it is given to 20 children, each one will receive four wafers and if there are 40 children, each one will receive two wafers. The pupil also made the total number of wafers 200. If there are 20 pupils, each child will receive 10 wafers and if there are 40 pupils, each child will receive five wafers. He was able to state that the value of $\mathrm{B}$ is $1 / 2$ of $\mathrm{A}$.

Table 2. Pupil's response

\begin{tabular}{ccc}
\hline \multicolumn{4}{c}{ Mathematical Sentence: $20 \times \mathrm{A}=40 \times \mathrm{B}$} \\
Total number of wafers & 20 children & 40 children \\
\hline 160 & 8 & 2 \\
80 & 4 & 4 \\
200 & 10 & 5 \\
\hline Relationship between A and B: B is $1 / 2$ of A
\end{tabular}

Table 3 shows the response of another pupil in the second part of the task. The mathematical sentence is $3(\mathrm{Y})=15(\mathrm{Z})$. If both the left and righties of the equation are equal to 30 , the value of $\mathrm{Y}$ is 10 and the value of $Z$ is 2 . If both the left and right sides of the equation are equal to 45, the value of $Y$ is 15 and the value of $\mathrm{Z}$ is 3 . And if both the left and right side of the equation is equal to 60 , the value of $\mathrm{Y}$ is 20 and the value of $\mathrm{Z}$ is 4 . The pupil was able to identify that the value of $\mathrm{Z}$ is one-fifth of the value of $\mathrm{Y}$.

Table 3. Pupil's response

\begin{tabular}{ccc}
\hline \multicolumn{3}{c}{ Mathematical sentence: $3(\mathrm{Y})=15(\mathrm{Z})$} \\
Value of equality & Constant: 3 & Constant: 15 \\
\hline 30 & $3(\mathrm{Y}) ; \mathrm{Y}=10$ & $15(\mathrm{Z}) ; \mathrm{Z}=2$ \\
45 & $3(\mathrm{Y}) ; \mathrm{Y}=15$ & $15(\mathrm{Z}) ; \mathrm{Z}=3$ \\
60 & $3(\mathrm{Y}) ; \mathrm{Y}=20$ & $15(\mathrm{Z}) ; \mathrm{Z}=4$ \\
\hline Relationship between $\mathrm{Y}$ and $\mathrm{Z}: \mathrm{Z}$ 's value is $1 / 5$ of $\mathrm{Y}$ 's value
\end{tabular}

\subsubsection{Pupils' responses to process questions}

After going through the lesson topic and activities, the pupils were asked to answer process questions. These process questions were focused on the pupils' realizations in the learning process. The following are the pupils' responses when asked the questions:

i) "What connection did you make today that made you say, 'AHA I get it!"”

"I have learned that there are countless ways to create the same numbers."

"The connection between X and Y: when the constant is changed the answer is changed." 
ii) "Something that I still do not understand is..."

"Nothing. Actually, I learned a lot from this lesson."

"Nothing, just practice more and more to improve."

iii) "In what ways did you see today's mathematics connected to your everyday life?"

"It helps to understand the concepts of balance more in my daily life."

"The balance is needed to make everything equal and not just focus on one side."

The responses indicated the extent of pupils' understanding of the lesson presented and discussed. It also showed pupils' confidence in building algebraic thinking from arithmetic. Lastly, the responses exhibited how the pupils were able to make a meaningful connection between the concept of algebra and algebraic equations to real life.

\subsection{Looking into the "big picture" and responding to relevant social issues could strengthen meaning- integration of Ignatian values}

Observers have appreciated that the integration of the Ignatian value in the research lesson plan and the implementation itself was smoothly done. Contrary to the usual claim of a mathematics teacher who finds difficulty infusing values in a math class [30], the Ignatian value "faith that does justice" was smoothly and clearly manifested in the discussion of "balancing" was explicitly identified by the pupils.

Teacher: "How does balancing work in your daily life?" "Where else do you experience balance?

Pupils: "balanced diet," "balance between academics and sports," "balance in managing time," "balance in thinking before making decisions," "fairness like balance in treating others."

Teacher: "So which Ignatian Value is reflected in today's lesson? Why do you say so?"

Pupil: "Faith that does Justice since it reflects fairness in dealing with others and balance in living one's life."

Using the orphan crisis as a relevant social issue where solving algebraic equations can be used gave more meaning to what the pupils are learning. Seeing connections and relevance of solving algebraic equations to real-life situations allowed pupils to see algebra in an easy perspective rather than looking at it too vaguely.

Though the presentation of the social issue was given less time and attention as it was written in the plan, the emphasis was made more on the aspect where mathematical problem solving was involved. The LS team decided upon such a change at the last minute due to time constraints. Also, according to two observers, the picture about the orphan crisis situation that was flashed on the screen was not clear enough for the pupils to see and understand. Lastly, the use of the wafers as part of the concrete approach in solving the identified problem situation was not used effectively.

Lastly, in giving better meaning to the lesson through its integration with the Ignatian value and social issue, according to one of the observers, it could have been best if the teacher allowed the pupils to reflect on the problem situation and ask, "if the number of children in two orphanages is not same, yet you have the same number of goods to share, how would the distribution to goods be? Will the children get the same number of goodies?" This reinforces the concept of equitable distribution of wealth, which is, too, part of the school's mission.

\section{CONCLUSION}

The process of using generalizable numbers of sentences as quasi-variables can allow pupils to make connections between arithmetic thinking and algebraic thinking. From focusing pupils' attention on numerical equality to identifying and discussing algebraic generalization, the lesson started with activating prior knowledge that focused on arithmetic before doing a formal introduction to algebra dealing with numbers as quasi-variable then eventually with literal symbols of algebra.

Connecting to broader aspects and integrating Ignatian values in every lesson in class are two fundamental parts of Jesuit education that require thorough planning. Ignatian values allow pupils to reflect on what they learn and achieve goals beyond themselves. Challenging as it is, the goal is to incorporate these values in smooth transitions without losing focus on the nature of the subject matter. 
Essential and significant as it came out be, lesson study is practiced among teachers and administrators within a school community to work collaboratively on a common goal that is to promote effective and meaningful teaching. It is a healthy avenue for teaching professionals who are not just within the same discipline but across other fields as well, to interact, brainstorm, share, listen and discuss ideas that serve as a holistic approach in teaching lessons in mathematics. Findings from this study showed that engagement in lesson study poses a promise to enhance the teaching of mathematics, which not only caters to developing critical thinking but also makes meaning and connections to the real world and the school's vision and mission. Moreover, it can also be concluded that the extent to which the Ignatian value and social issue is integrated into the mathematics lesson for more meaning could have been given more emphasis through activities that could have allowed the pupils to discover and express such reflections themselves. The lesson study team believes that conducting a lesson study in developing a meaningful strategy and activity to achieve such is very helpful as it provides an efficient structure in developing a chosen lesson topic.

\section{ACKNOWLEDGEMENTS}

The authors would like to express their heartfelt gratitude to all those who contributed in the completion of this research study. To the Ateneo de Davao University Community, for the endless support and active partcipation in the process, from the implementation of the lesson study to the completion of the research paper.

\section{REFERENCES}

[1] S. Mountin and R. Nowacek, "Reflection in Action: A Signature Ignatian Pedagogy for the 21st Century," in N. L Chick, A. Haynie, and R. A. R. Gurung, Eds., Exploring More Signature Pedagogies: Approaches to Teaching Disciplinary Habits of Mind. Sterling, Va.: Stylus Publishing, 2012, pp. 129-142.

[2] Z. Lu and V. Rosen, "Practicing Ignatian Pedagogy: A Digital Collection of Resources," Jesuit Higher Education: A Journal, vol. 4, no. 2, pp. 135-152, 2015.

[3] Saint Louis University (SLU), Ignatian Pedagogical Paradigm. [Online]. Available: https://www.slu.edu/cttl/resources/ignatian-pedagogical-paradigm.php.

[4] M. McAvoy, "Training faculty to adopt the Ignatian pedagogical paradigm, IPP and its influence on teaching and learning: Process and outcomes," Jesuit Higher Education: A Journal, vol. 2, no. 2, pp. 1-12, 2013.

[5] L. Claywell, K. Pennington, and C. Spade, "An Exploration of the Influence of Ignatian Values on Faculty Role Expectations," Jesuit Higher Education: A Journal, vol. 3, no. 1, pp. 1-8, 2014.

[6] J.W. Mulnix, "Thinking critically about critical thinking," Educational Philosophy and Theory, vol. 44, no. 5, pp. 464-479, 2012, doi: 10.1111/j.1469-5812.2010.00673.x.

[7] Y. M. Abd Algani and J. Eshan, "Teaching Values via the Problem-Solving Approach in Mathematics," International Journal of Latest Research in Engineering and Technology (IJLRET), vol. 5, no. 10, pp. 1-11, 2019.

[8] D.G. Aniban, V.C. Chua, J. Garcia, and L.E. Elipane, "From Arithmetic to Algebra: Sequences and Patterns as an Introductory Lesson in Seventh Grade Mathematics," Paper presented at the Annual Meeting of the Mathematics Education Research Group of Australasia (MERGA), 2014.

[9] G. E. A. Don, "Secondary School Students' Misconceptions in Algebra," Dissertation, University of Toronto, 2011.

[10] S. Strachota, E. Knuth, and M. Blanton, "Cycles of generalizing activities in the classroom," In Teaching and Learning Algebraic Thinking with 5-to 12-Year-Olds. Springer International Publishing, 2018, pp. 351-378.

[11] N. Herscovics and L. Linchevski, "A cognitive gap between arithmetic and algebra," Educational Studies in Mathematics, vol. 27, no. 1, pp. 59-78, 1994, doi: 10.1007/BF01284528.

[12] P. Singh, C.T. Han, N.A. Nasir, M.A. Ramly, and T.S. Hoon, "Factors Contributing to Students' Poor Performance in a Mathematics Preparatory Program," 7th International Conference on University Learning and Teaching (InCULT 2014) Proceedings, 2016, pp. 349-360.

[13] B. Dougherty, D.P. Bryant, B.R. Bryant, R.L. Darrough, and K.H. Pfannenstiel, "Developing concepts and generalizations to build algebraic thinking: The reversibility, flexibility, and generalization approach," Intervention in School and Clinic, vol. 50, no. 5, pp. 273-281, 2015.

[14] G. Egodawatte, "Secondary school students' misconceptions in algebra," Unpublished Ph.D. Thesis, University of Toronto, Canada, 2011.

[15] M. Blanton, A. Stephens, E. Knuth, A.M. Gardiner, I. Isler, and J.S. Kim, "The development of children's algebraic thinking: The impact of a comprehensive early algebra intervention in third grade," Journal for Research in Mathematics Education, vol. 46, no. 1, pp. 39-87, 2015, doi: 10.5951/jresematheduc.46.1.0039.

[16] J.D. Vermunt, M. Vrikki, N. van Halem, P. Warwick, and N. Mercer, "The impact of Lesson Study professional development on the quality of teacher learning," Teaching and Teacher Education, vol. 81, no. 81, pp. 63-73, 2019, doi: 10.1016/j.tate.2019.02.009.

[17] L.S. Lomibao, "Enhancing mathematics teachers' quality through Lesson Study," SpringerPlus, vol. 5, no. 1, pp. 1-13, 2016, doi: 10.1186/s40064-016-3215-0. 
[18] L.E. Elipane, "Towards the embodiment of competency standards: Incorporating the elements of Lesson Study in the pre-service mathematics teacher education in the Philippines," The Asia-Pacific Education Researcher, vol. 21, no. 2, pp. 365-74, 2012.

[19] L.E. Elipane, "Introducing Lesson Study as a Professional Development Model in the Islands of the Philippines," Advanced Science Letters, vol. 23, no. 2, pp. 1126-9, 2017, doi: 10.1166/asl.2017.7514.

[20] L. Elipane, L. Nacino, R. Pereda, P. Reperuga, and M. Torio, "Developing Deep Mathematics Teaching Discourse Through Research Lessons," Proceedings of the 8th International Conference on Education Research, 2013, pp. 286-292.

[21] C. Lewis, R. Perry, J. Hurd, “A deeper look at lesson study” Educational leadership, vol. 61, no. 5, p. 18, 2004

[22] H. Joffe, Thematic analysis, Qualitative research methods in mental health and psychotherapy. John Wiley \& Sons, Ltd 2012, doi: 10.1002/9781119973249.ch15.

[23] M.L. Fernandez, "Investigating how and what prospective teachers learn through microteaching lesson study," Teaching and Teacher Education, vol. 26, no. 2, pp. 351-62, 2010, doi: 10.1016/j.tate.2009.09.012.

[24] S.B. Gutierez, "Teachers' reflective practice in lesson study: A tool for improving instructional practice," Alberta Journal of Educational Research, vol. 61, no. 3, pp. 314-328, 2015.

[25] W. Widjaja, C. Vale, S. Groves, and B. Doig, "Teachers' professional growth through engagement with lesson study," Journal of Mathematics Teacher Education, vol. 20, no. 4, pp. 357-83, 2017, doi: 10.1007/s10857-0159341-8.

[26] A. Takahashi and T. McDougal, "Collaborative lesson research: Maximizing the impact of lesson study," ZDM: Mathematics Education, vol. 48, no. 4, pp. 513-26, 2016, doi: 10.1007/s11858-015-0752-x.

[27] W.H. Chong and C.A. Kong, "Teacher collaborative learning and teacher self-efficacy: The case of lesson study," Journal of Experimental Education, vol. 80, no. 3, pp. 263-283, 2012.

[28] C.T. Doabler and H. Fien, "Explicit mathematics instruction: What teachers can do for teaching students with mathematics difficulties?" Intervention in School and Clinic, vol. 48, no. 5, pp. 276-85, 2013, doi: $10.1177 / 1053451212473151$.

[29] P. Andrews and J. Sayers, "Teaching linear equations: Case studies from Finland, Flanders and Hungary," The Journal of Mathematical Behavior, vol. 31, no. 4, pp. 476-488, 2012, doi: 10.1016/j.jmathb.2012.07.002.

[30] C.P. Dwyer, M.J. Hogan, and I. Stewart, "An integrated critical thinking framework for the 21 st century," Thinking Skills and Creativity, vol. 12, pp. 43-52, 2014, doi: 10.1016/j.tsc.2013.12.004. 